\title{
UNIVERSITYOF
}

FORWARD

THINKING

WESTMINSTER用

WestminsterResearch

http://www.westminster.ac.uk/westminsterresearch

Aligned nanofibres made of poly(3-hydroxybutyrate) grafted to hyaluronan for potential healthcare applications

Huerta-Ángeles, G., Knotková,, K., Knotek, P., Židek, O.,

Brandejsová, M., Pokorný, M., Vagnerová, H., Roy, I. and Velebný, V.

This is an author's accepted manuscript of an article published in Journal of Materials Science: Materials in Medicine, (2018) 29: 32. https://doi.org/10.1007/s10856-018-6045$\underline{5}$

The final publication is available at Springer via:

https://dx.doi.org/10.1007/s10856-018-6045-5

The WestminsterResearch online digital archive at the University of Westminster aims to make the research output of the University available to a wider audience. Copyright and Moral Rights remain with the authors and/or copyright owners.

Whilst further distribution of specific materials from within this archive is forbidden, you may freely distribute the URL of WestminsterResearch: ((http://westminsterresearch.wmin.ac.uk/)).

In case of abuse or copyright appearing without permission e-mail repository@westminster.ac.uk 


\section{Aligned nanofibres made of poly(3-hydroxybutyrate) grafted to hyaluronan for potential healthcare applications}

Gloria Huerta-Ángeles, ${ }^{a}$ Kateřina Knotková, ${ }^{a}$ Petr Knotek, ${ }^{\mathrm{b}}$ Ondrej Židek, ${ }^{a}$ Martina Brandejsová, ${ }^{a}$ Marek Pokorný, ${ }^{a}$ Hana Vagnerová, ${ }^{a}$ Ipsita Royc and Vladimir Velebnýc

${ }^{a}$ Contipro a.s., Dolní Dobrouč 401, 56102 Dolní Dobrouč, Czech Republic

bUniversity of Pardubice, Faculty of Chemical Technology, Department of General and Inorganic Chemistry, Studentská 573, 532 10, Pardubice, Czech Republic

${ }^{\mathrm{c}}$ Department of Life Science, Faculty of Science and Technology, University of Westminster, 115 New Cavendish Street, London W1W 6UW, United Kingdom

\section{Acknowledgements}

This research has received funding from the European Community's Seventh Framework Programme (FP7-NMP2013-SME-7) under grant agreement no 604450 (NEURIMP "Novel combination of biopolymers and manufacturing technologies for production of a peripheral nerve implant-containing an internal aligned channels array"). The authors would like to thank Lenka Hejlová, Pavlína Halamková, Jaroslav Novotný and Drahomira Chládková (Contipro a.s.), for the technical support. Special thanks also go to Barbara Lukasiewicz, Pooja Basnett and Rinat Nigmatullin (UoW) for their work on PHAs. 


\begin{abstract}
In this work, a hybrid copolymer consisting of poly(3-hydroxybutyrate) grafted to hyaluronic acid (HA) was synthesised and characterised. Once formed, the P(3HB)-g-HA copolymer was soluble in water allowing a green electrospinning process. The diameters of nanofibres can be tailored by simply varying the $\mathrm{M}_{\mathrm{w}}$ of polymer. The optimization of the process allowed to produce fibres of average diameter in the range of $100-150 \mathrm{~nm}$ and low polydispersity. The hydrophobic modification has not only increased the fibre diameter, but also the obtained layers were homogenous. At the nanoscale, the hybrid copolymer exhibited an unusual hairy topography. Moreover, the hardness and tensile properties of the hybrid were found to be superior compared to fibres made of unmodified HA. Particularly, this reinforcement was achieved at the longitudinal direction. Additionally, this work reports the use in the composition of a water-soluble copolymer containing photo cross-linkable moieties to produce insoluble materials post-electrospinning. The derivatives as well as their nanofibrous mats retain the biocompatibility of the natural polymers used for the fabrication.
\end{abstract}




\section{Introduction}

Bioresorbable mats made from degradable polymers are clinically desirable because they do not need to be removed after healing. Among these polymers, the Polyhydroxyalkanoate family (PHAs) are natural polyesters (1) that have received great attention due to their potential use as medical implantation devices $(2,3)$. In addition, poly(R3-hydroxybutyrate), $\mathrm{P}(3 \mathrm{HB})$, the most common member of PHA family had demonstrated to be fully biodegradable and compatible. Although, $\mathrm{P}(3 \mathrm{HB})$ has not been fully utilized in biomedical field due to its stiff and brittle nature (4).

On the other hand, through chemical modification or blending by the inclusion of other polymers tunable properties can be derived (5). Particularly, graft copolymerization had been used to obtain a polymer with the desired properties. However, the biocompatibility issues have not yet been solved (6). For that reason, hyaluronan or hyaluronic acid (HA), a glycosaminoglycan composed of repeating disaccharide units of N-acetyl-D-glucosamine (GlcNAc) and Dglucuronic (GlcA) linked by glycosidic bonds ([4)- $\beta-D-G l c p A-(13)-\beta-D-G l c p N A c-(1] n)$, an ubiquitous biopolymer found in the human body represents an advantageous candidate for biomedical applications. Moreover, HA is involved in the wound healing process and scarring (7). Previously, we have described the "grafting onto" strategy to covalently bond low molecular weight poly(3-hydroxyalkanoates) $\left(\mathrm{M}_{\mathrm{w}}=2000-5000\right)$ to HA towards drug delivery (8). With the presence of $\mathrm{HA}$, the hybrid $\mathrm{P}(3 \mathrm{HB})-g$-HA became water soluble by tailoring the percentage of modification.

On the other hand, one of the most powerful biofabrication techniques is electrospinning (9). Electrospun nanofibrous layers have superior cell adhesion, proliferation, and differentiate more efficiently due to their high surface/volume ratio, therefore, the obtained scaffolds have demonstrated great potential in tissue engineering (10). Moreover, this technique could address reproducibility and scale-up issues (11).

In this study, we aimed to create a nano structured hybrid material using electrospun nanofibres of made of $\mathrm{P}(3 \mathrm{HB})-\mathrm{g}$-HA. The measurements presented in this paper are reported after optimising the electrospinning parameters. The use of water as a green solvent for the processing will be demonstrated towards potential application in biomedical field. The morphology of the nanofibrous mats was evaluated by scanning electron microscopy (SEM), and atomic force microscopy (AFM). The mechanical reinforcement was demonstrated by nanoindentation and tensile analysis, to find possible variations in the composition and nanofibre size. Finally, to produce insoluble materials post electrospinning, functionalized HA-containing moieties for cross-linking have been introduced in the composition. 
This work specially highlights the finding that hydrophobic modification can enhance the mechanical properties of HA nanofibres without losing the biocompatibility.

\section{Materials and Methods}

\subsection{Processing of material by electrospinning}

Hyaluronic acid $(\mathrm{Mw}=15,000 \mathrm{~g} / \mathrm{mol}(\mathrm{Mw} / \mathrm{Mn}=1.6), \mathrm{HA}$ of $\mathrm{Mw}=82,000 \mathrm{~g} / \mathrm{mol}(\mathrm{Mw} / \mathrm{Mn}=1.5)$ provided by Contipro a.s. (Dolni Dobrouc, Czech Republic), or P(3HB)- $g$-HA prepared as described in supplementary part S2.2 was blended with Polyethylene oxide (PEO: $\mathrm{Mw}=400,000 \mathrm{~g} / \mathrm{mol}$ ) obtained from Scientific Polymer Products, Inc. (Ontario, NY) in ratio (8:2). So that, the final concentration was 6,7 or $11 \mathrm{wt} \%$. After $24 \mathrm{~h}$ of gentle stirring at $25^{\circ} \mathrm{C}$, the solutions were electrospun by using the 4SPIN device (12). The solution was dosed via a spinning nozzle (21 gauge, Hamilton). The nozzle was connected to a high voltage source with a voltage set up to $\mathrm{V}=55 \mathrm{kV}$ ( $\mathrm{E}=306$ $\mathrm{kV} / \mathrm{m}$ ). The distance between collector and emitter was $20 \mathrm{~cm}$, the collector speed was $3000 \mathrm{rpm}$. The used voltage, flow rate and dosing for each experiment are summarised in Table 1, which were optimized to ensure that the process would be stable and reproducible. The hybrid P(3HB)-g-HA was mixed with 3-(2-furyl) acrylic acid hyaluronan (HAFU) (50/50) to obtain water insoluble nanofibre mats. The preparation and characterisation of the copolymers were included in supplementary part (S2.2 and S2.3). The $\mathrm{P}(3 \mathrm{HB})$ solution was prepared from DMF/chloroform in $10 \mathrm{wt} \%$ concentration. Ambient parameters were preestablished and controlled during the experiments i.e. humidity (15-18\%) and temperature $\left(24-25^{\circ} \mathrm{C}\right)$ and set up in the electrospinning apparatus (13).

\section{Results}

\subsection{Effect of the covalent bonding of HA and poly(3-hydroxybutyrate).}

The preparation of the copolymer $\mathrm{P}(3 \mathrm{HB})-g$-HA useful for electrospinning was optimized using the procedure reported before (8). The first step of this condensation reaction is the activation of the carboxyl moiety in dimethylsulphoxide (DMSO) and is followed by the esterification of HA (Figure 1) in water. The hybrid copolymers were characterized by ${ }^{1} \mathrm{H}$ NMR spectroscopy in $\mathrm{D}_{2} \mathrm{O}$ (Figure S1). ${ }^{1} \mathrm{H}$ NMR was also used for the determination of grafting degree (GD), expressed in \% and defined as an average number of $\mathrm{P}(3 \mathrm{HB})$ chains attached to 100 disaccharide HA dimers. For example, GD $=5.2 \%$ indicates that 5 out of 100 disaccharide HA dimers were modified. The presence of covalent bonding between HA and P(3HB) was demonstrated by DOSY (Figure S2). Hydrolytic depolymerisation 
of $\mathrm{P}(3 \mathrm{HB})$ was used for the synthesis of defined oligo(3-hydroxybutyrate)-containing carboxylic terminal moieties (8). Particularly, the results showed that $\mathrm{P}(3 \mathrm{HB})$ with short grafting length $\left(\mathrm{M}_{\mathrm{w}}=2.2 \times 10^{3} \mathrm{~g} / \mathrm{mol}\right)$ was particularly useful for the synthesis of the hybrids used in this work. Table 1 contains the molecular weight $\left(\mathrm{M}_{\mathrm{w}}\right)$ and polydispersity $\left(\mathrm{M}_{\mathrm{w}} / \mathrm{M}_{\mathrm{n}}\right)$ of the polymers $\mathrm{P}(3 \mathrm{HB})$ - $g$-HA used in this work. Furthermore, the covalent modification affected the thermal properties of the polymers, as shown by differential scanning calorimetry (DSC) and thermogravimetric analyses (TGA) in Figures S3 and S4. DSC demonstrated that the copolymer was amorphous, which can result in an advantage because $\mathrm{P}(3 \mathrm{HB})$ tends to crystallize during its processing. The TGA thermogram of HA represented two stages of weight loss. The first stage of weight loss $(15 \% \mathrm{w} / \mathrm{w})$ occurred between room temperature to $218^{\circ} \mathrm{C}$ due to the evaporation of bond water and structural water. A second stage was a sharp increase from $220^{\circ} \mathrm{C}$ to $590.9^{\circ} \mathrm{C}$, probably due to the degradation of the skeletal HA. The degradation of the hybrid $\mathrm{P}(3 \mathrm{HB})-$ $g$-HA consisted of three stages. The first stage of weight loss was at $198.3^{\circ} \mathrm{C}$, the second one at $350^{\circ} \mathrm{C}$, while a third drastic loss of weight was observed at $500^{\circ} \mathrm{C}$. The last one is attributed to the cleavage of ester bonds in hybrid, which required higher degradation temperatures $\left(350-450^{\circ} \mathrm{C}\right)(14)$. Also, the copolymers have lower onset temperature values than their precursors (15). Because of the amphiphilicity of the prepared hybrid, the fraction of $\mathrm{P}(3 \mathrm{HB})$ was kept up to $13 \pm 2 \%$ to allow the derivative to be fully soluble in water. 


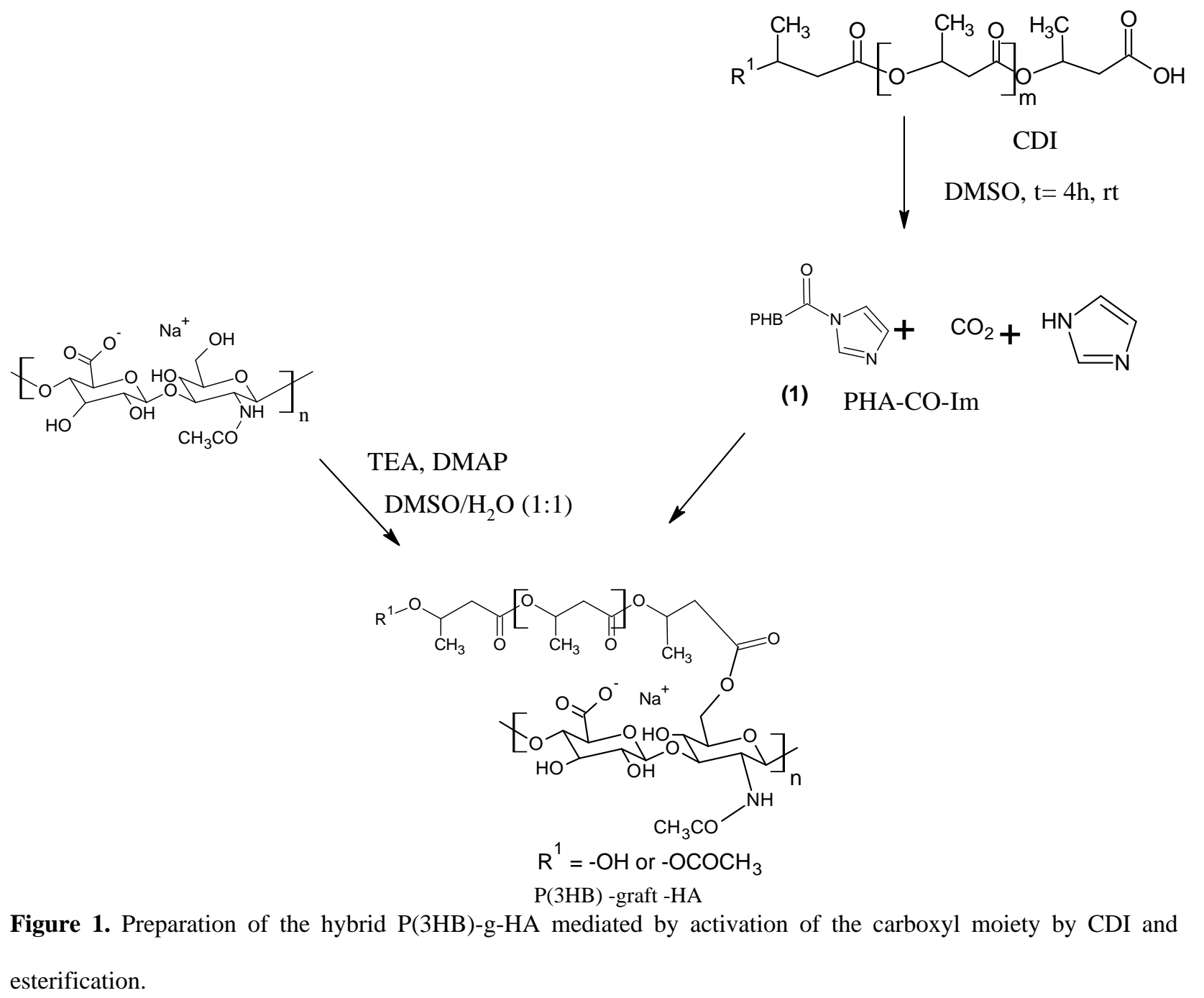

\subsection{Tuning the fibre diameter of $\mathbf{P}(3 \mathrm{HB})$-grafted-hyaluronan based scaffolds}

As the electrospinning was severely affected by the concentration of HA, the effect of concentration was studied (6.0, 7.0 and $11 \mathrm{wt} \%$ ) and prepared according to the $\mathrm{M}_{\mathrm{w}}$ of the polymer. The hybrid was successfully processed by using voltages of $30-55 \mathrm{kV}$ and produced aligned polymer jets. Table 1 summarizes the results obtained for the optimized electrospinning parameters. As shown in Figure 2, neat $\mathrm{HA}_{82}$ nanofibres were obtained by using 6 wt. \% solution with a mean fibre diameter of $116 \pm 23 \mathrm{~nm}$. While, the average diameter of nanofibres produced with $\mathrm{P}(3 \mathrm{HB})$ $g$-HA were $132 \pm 21 \mathrm{~nm}$ for $\mathrm{DG}=8.3 \%$ and $142 \pm 26 \mathrm{~nm}$ for $\mathrm{DG}=12.8 \%$ and the lowest polydispersity of all the tested conditions (data not shown). The presence of $\mathrm{P}(3 \mathrm{HB})$ in the copolymers increased slightly the diameter of the resulting nanofibres probably explained by the decrease of charge density caused by the presence of the hydrophobic polymer (16). 

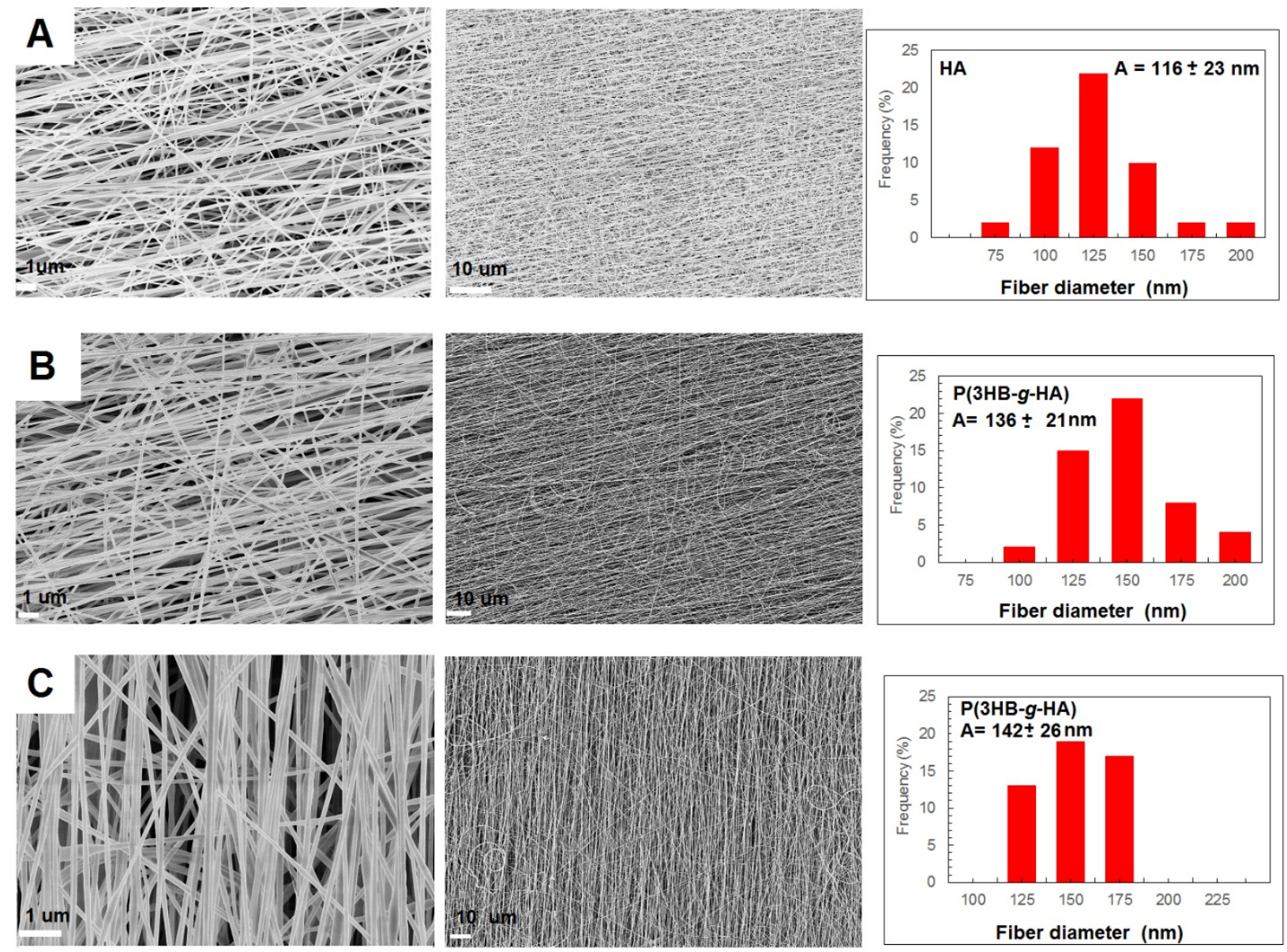

Figure 2. SEM images and fiber diameter distributions with average fiber diameter $(n m) \pm S D(n=50)$ of electrospun nanofibers obtained from solutions of (A) HA, (B) P(3HB)- $g$-HA (GD= $8.3 \%$ ) and (C) $\mathrm{P}(3 \mathrm{HB})-g$-HA (GD=12.8\%). Scale bars: 1 and $10 \mu \mathrm{m}$.

On the other hand, $\mathrm{HA}_{15}$ produced nanofibres with fibre diameter of $303 \pm 44 \mathrm{~nm}$ (Table 1, entry 1). The hybrid $\mathrm{P}(3 \mathrm{HB})-\mathrm{g}$-HA nanofibres have also increased the mean fibre diameter to $324 \pm 41 \mathrm{~nm}(\mathrm{GD}=5.0 \%)$ and $334 \pm 87$ $\mathrm{nm}(\mathrm{GD}=10.2 \%)$, respectively. Interestingly, increasing DS also increased the fibre diameter. At last, neat $\mathrm{P}(3 \mathrm{HB})$ was also processed. The results showed that the obtained fibres were larger $7160 \pm 335 \mathrm{~nm}$ (Figure S5). Thus, it is challenging to produce $\mathrm{P}(3 \mathrm{HB})$-based fibres in the nanoscale as observed before (17). A key feature of native extracellular matrix (ECM) is the nanoscale dimension of its internal components (18). Thus, a potential substitute is expected to mimic its properties.

Table 1. Material identification, electrospinning parameters and resulting fibre diameters 


\begin{tabular}{|c|c|c|c|c|c|c|c|c|c|}
\hline $\begin{array}{l}\text { Entr } \\
\mathrm{y}\end{array}$ & $\begin{array}{c}\text { Polymer or } \\
\text { blend }\end{array}$ & $\begin{array}{l}\mathrm{GD}^{\mathrm{b}} \\
(\%)\end{array}$ & $\begin{array}{l}10^{3} \mathrm{Mw}^{\mathrm{c}} \\
{\left[\mathrm{g} \mathrm{mol}^{-1}\right]} \\
(\mathrm{Mw} / \mathrm{Mn})\end{array}$ & $\begin{array}{l}\text { Conc. }^{\mathrm{d}} \\
(\% \mathrm{wt} .)\end{array}$ & $\begin{array}{c}\text { Voltage } \\
(\mathrm{kV})\end{array}$ & $\begin{array}{c}\text { Distance }^{e} \\
(\mathrm{~cm})\end{array}$ & $\begin{array}{c}\text { Solution } \\
\text { flow rate } \\
(\mu \mathrm{L} / \mathrm{min})\end{array}$ & $\begin{array}{l}\text { Collector } \\
\text { Speed } \\
(\mathrm{rpm})\end{array}$ & $\begin{array}{c}\text { fibre } \\
\text { diameter } \pm \\
\mathrm{SD}(\mathrm{nm})^{\mathrm{f}}\end{array}$ \\
\hline 1 & $\mathrm{HA}_{15} / \mathrm{PEO}_{400}$ & 0 & $15(1.2)$ & 11 & 30 & 20 & 40 & 3000 & $303 \pm 44$ \\
\hline 1a & $\mathrm{P}(3 \mathrm{HB})-\mathrm{g}-\mathrm{HA}$ & $5.0 \pm 0.5$ & $13.4(1.3)$ & 11 & 30 & 20 & 50 & 3000 & $324 \pm 41$ \\
\hline $\mathbf{1 b}$ & & $\begin{array}{c}10.2 \pm 0 \\
4\end{array}$ & $17.9(1.8)$ & 11 & 30 & 20 & 30 & 3000 & $334 \pm 87$ \\
\hline 2 & $\mathrm{HA}_{82} / \mathrm{PEO}_{400}$ & 0 & $82(1.4)$ & 6 & 55 & 20 & 35 & 3000 & $116 \pm 23$ \\
\hline $2 a$ & $\mathrm{P}(3 \mathrm{HB})-\mathrm{g}-\mathrm{HA}$ & $6.8 \pm 0.3$ & $84(1.9)$ & 6 & 55 & 20 & 35 & 3000 & $130 \pm 31$ \\
\hline $2 b$ & & $8.3 \pm 0.3$ & $79.2(1.5)$ & 6 & 30 & 20 & 30 & 3000 & $136 \pm 21$ \\
\hline $2 c$ & & $\begin{array}{c}12.9 \pm 0 . \\
5\end{array}$ & $78.8(1.2)$ & 6 & 55 & 20 & 35 & 3000 & $142 \pm 26$ \\
\hline 3 & $\begin{array}{l}\mathrm{P}(3 \mathrm{HB})-g-\mathrm{HA} \\
/ \mathrm{HA}^{-} \mathrm{Fu}_{82} / \\
\mathrm{PEO}_{400}\end{array}$ & $\begin{array}{l}6.8 \pm 0.3 / \\
5.0 \pm 0.5\end{array}$ & $\begin{array}{l}79.2(1.5) \\
78.2(1.5)\end{array}$ & 6 & 50 & 20 & 100 & 3000 & $133 \pm 22$ \\
\hline 4 & $\mathrm{P}(3 \mathrm{HB})$ & 0 & $273.5(1.7)$ & 10 & 12 & 15 & 70 & 2500 & $7160 \pm 335$ \\
\hline
\end{tabular}

a all the HA solutions contained (20\% wt.) of PEO $(400,000 \mathrm{~g} / \mathrm{mol})$

${ }^{\mathrm{b}}$ grafting degree determined by NMR is an average of at least three independent experiments

${ }^{c}$ the average molecular weight and polydispersity (PDI) of native HA and PHB used for modification was

determined before the chemical modification; $\mathrm{Mw}=$ weight average molecular weight; $\mathrm{Mn}=$ number average

molecular weight; $\mathrm{P}=$ polydispersity index $(\mathrm{Mw} / \mathrm{Mn})$.

${ }^{d}$ Final concentration of the material in the used solvent. All the hyaluronan derivates were dissolved in water and $\mathrm{P}(3 \mathrm{HB})$ was dissolved in a mixture of DMF/Chloroform (1:1).

edistance from the spinneret to the collector.

${ }^{\mathrm{f}}$ the average fiber diameter $(\mathrm{nm}) \pm \mathrm{SD}(\mathrm{n}=50)$

In view of correlation between the structural integrity of scaffolds and cells growth, there was need to investigate the mechanical properties of the scaffolds. For that reason, the mechanical properties of HA and the hybrid were compared. Mechanical properties were determined by AFM and tensile stress. Both methods, confirmed that the hybrid P(3HB)- $g$-HA/PEO material exhibits a two-fold higher stiffness in comparison to the blend HA/PEO (Figs. 3 and 4). Moreover, Figs. 3A and 3B depicted the topography of the nanofibres. Nanofibres made of native HA presented a smooth structure, while $\mathrm{P}(3 \mathrm{HB})-\mathrm{g}$-HA is distinguished by forming branching aggregates. The stiffness of the material is independent of the diameter (diameter range from 100 to $400 \mathrm{~nm}$ ) and is higher for the hybrid (Figure 3C). 

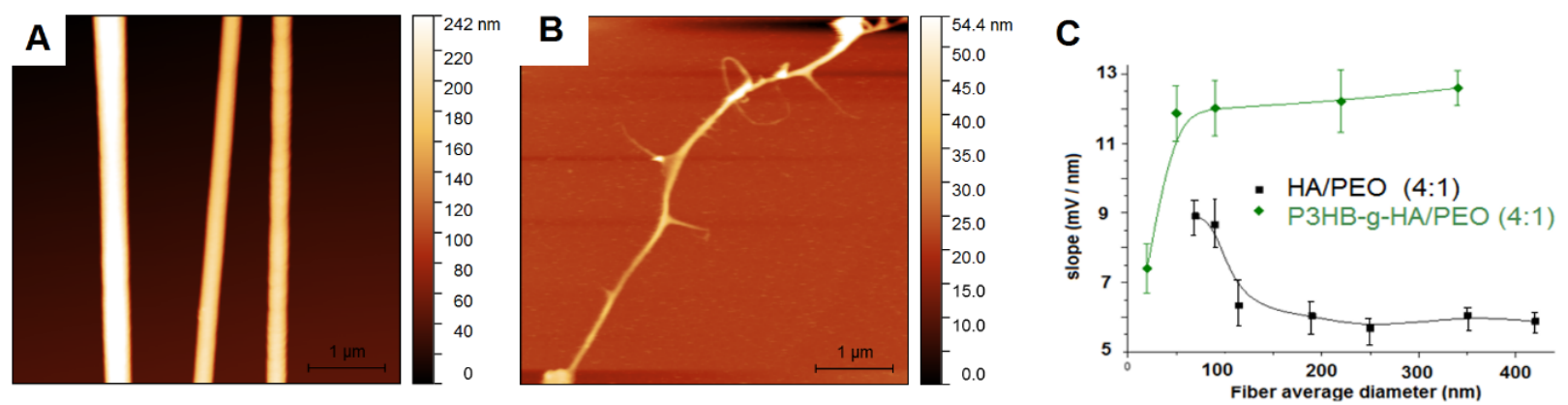

Figure 3. (A) Topography of HA based-fibres and (B) topography of $\mathrm{P}(3 \mathrm{HB})-g$-HA corresponding to Table 1, entry $2 \mathrm{C}$ (scans $5 \times 5 \mathrm{~m}^{2}$ ) and (C) comparison of the material stiffness showed as the slope of the force-distance curve.

A representative curve compared the extensibility of HA and the hybrid (Figure 4). Aligned fibres made of the hybrid were preferentially reinforced in the direction parallel to the fibre axis. In addition, the orientation of the fibres has also been shown to improve its tensile strength of the construct compared to randomly oriented fibres (Table S1). Aligned fibres made of P3HB- $g-\mathrm{HA}_{78} / \mathrm{PEO}$ showed a tensile stress of $1420.2 \pm 21.4 \mathrm{MPa} / \mathrm{g}$ in the longitudinal direction while $\mathrm{HA}_{82} / \mathrm{PEO}_{400}$ shows only $570.3 \pm 42 \mathrm{MPa} / \mathrm{g}$. At the transverse direction, the hybrid showed $130.2 \pm$ 16.7 MPa/g. While $\mathrm{HA}_{82} / \mathrm{PEO}_{400}$ displays $109.0 \pm 12.2 \mathrm{MPa} / \mathrm{g}$.
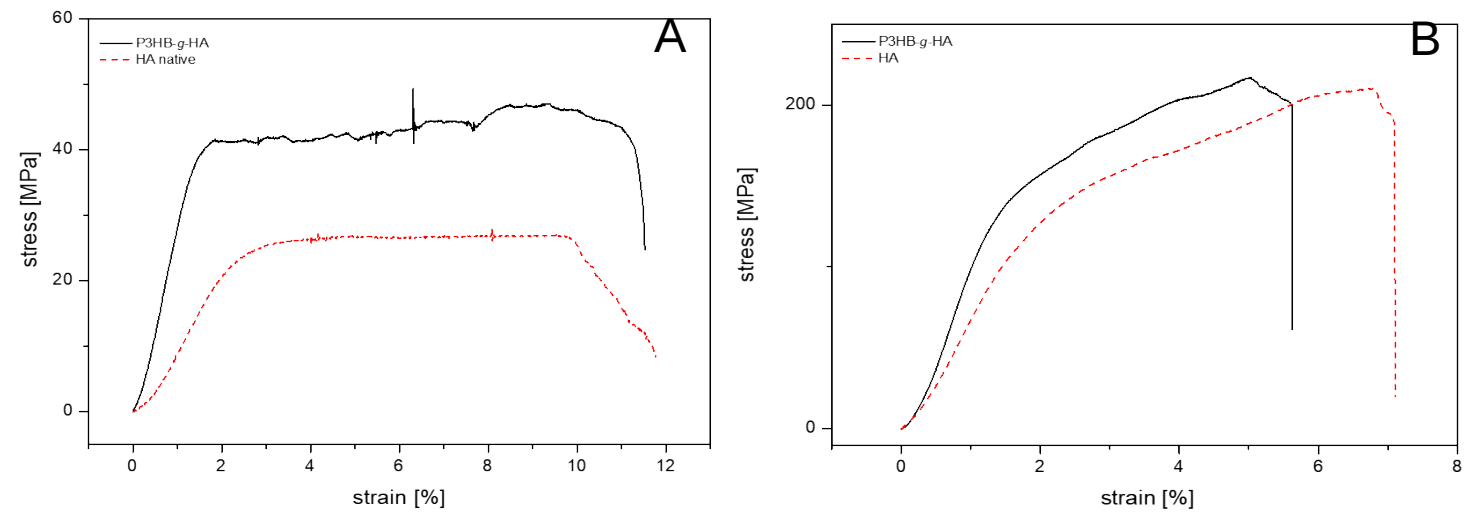

Figure 4. Stress-strain curves of $\mathrm{HA}$ and hybrid $\mathrm{P}(3 \mathrm{HB})$-g-HA corresponding to Table 1 , entry $2 \mathrm{C}(\mathrm{A})$ in the transverse direction and (B) in the longitudinal direction of the fibres. 
The last method for characterising the nanofibres was an estimation of what would happen if cells came in direct contact with the nanofibrous mats. Thus, the in vitro cytotoxicity of the mats was assessed in accordance with ISO 10993. Cross-linking was used to avoid the disintegration of the material when exposed to an aqueous environment. For that reason, $\mathrm{P}(3 \mathrm{HB})-\mathrm{g}$-HA was further blended with HA-FU and cross-linked by UV irradiated postelectrospinning (Figure 5), following a procedure described recently by our group (19).
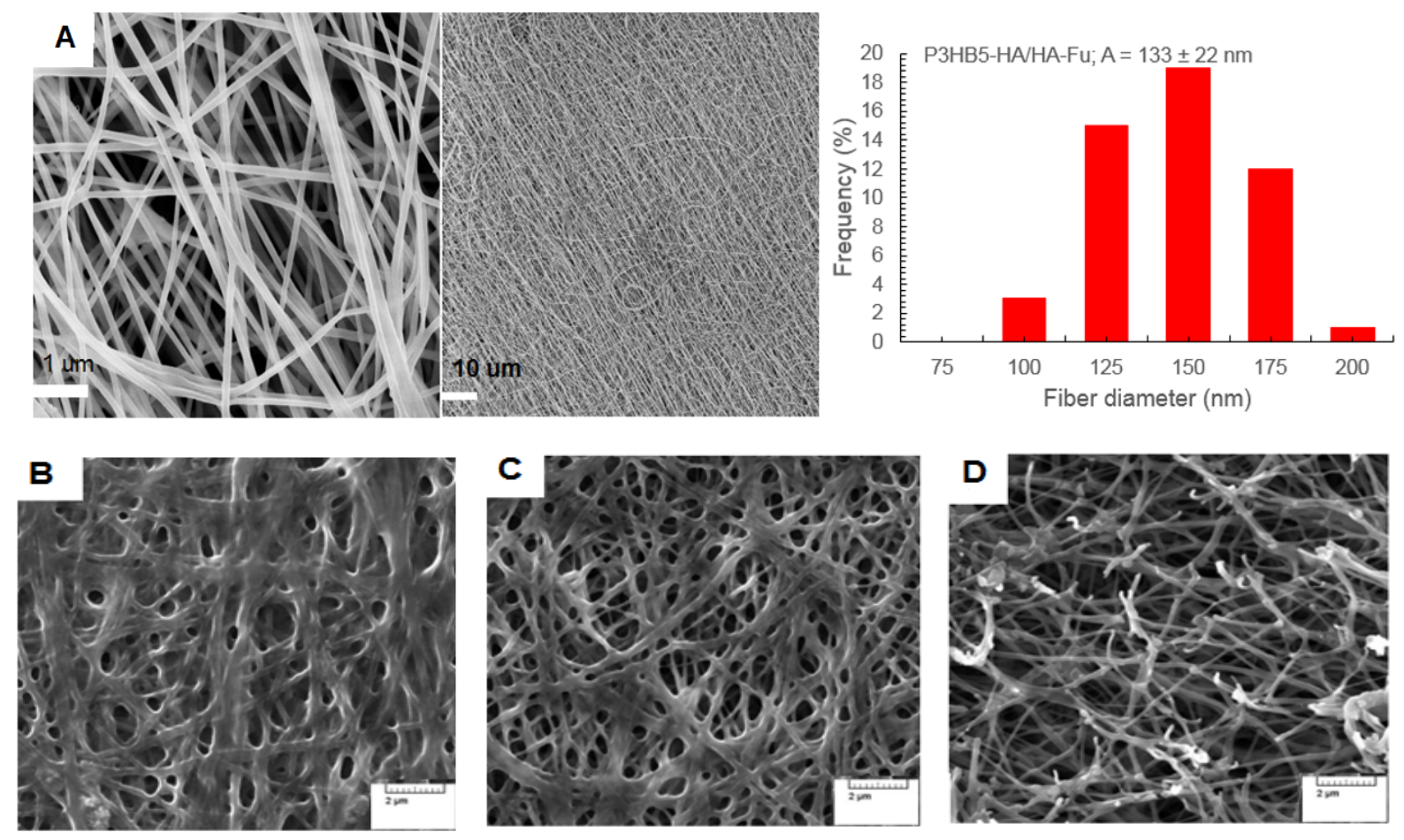

Figure 5. A) SEM micrograft of fibers in dry state and after B) 5, C)10 and D) 40 minutes, respectively of UVirradiation at $320 \mathrm{~nm}$. The nanofibrous scaffolds were soaked in water and dried for the analysis structural.

It is worth to mention that the incorporation of HA-FU did not alter the average diameter size of the nanofibres neither the homogeneity (Figure 5A). Furthermore, the proliferation of cells in contact with the cross-linked nanofibres were assessed after 24h of culture and not cytotoxic effect was observed (Figure S7).

\section{Discussion}

Currently, numerous studies have demonstrated that $\mathrm{P}(3 \mathrm{HB})$ is able to contribute positively to cell attachment and growth (20). Nonetheless, the applications of neat $\mathrm{P}(3 \mathrm{HB})$ are limited to applications which prefer a hydrophobic and crystalline substrate (21). Previous reports have shown that the porous surface of films made of $\mathrm{P}(3 \mathrm{HB}) / \mathrm{HA}$ blends 
promoted significantly the growth of keratinocytes, and yet the resulting material was stiffer and more brittle (22). In contrast, to previously described works describing the process of $\mathrm{P}(3 \mathrm{HB})$ in toxic fluorinated/chlorinated solvents which are not ideal for biomedical applications (23). In this work the hybrid (P(3HB)-g-HA) was processed by electrospinning in water. This process is mostly affected by viscosity of the solution, which largely influences the surface tension and conductivity. Hence, the effect of molecular weight of the polymer was studied, using the average fibre diameter observed by SEM to evaluate its influence. $\mathrm{HA}_{15} / \mathrm{PEO}_{400}$ and $\mathrm{P}(3 \mathrm{HB})$ - $g$ - $-\mathrm{HA}_{15} / \mathrm{PEO}_{400}$ produced nanofibres that were characterized by average diameter from 300 to $350 \mathrm{~nm}$ (Table 1, entries 1, 1a-1b). While, the processing of $\mathrm{P}(3 \mathrm{HB})-g-\mathrm{HA}_{78} / \mathrm{PEO}_{400}$ produced fibres characterized by smaller average diameter $(142 \pm 26 \mathrm{~nm})$ and homogeneous polydispersity (Table 1, entries 2 and 2a-2c). Thus, the hydrophobic modification resulted in an increase in the fibre diameter. The obtained nanofibrous layers were homogenous due to the good solubilisation of the conjugate in water in relatively high concentration (up to $11 \mathrm{wt} \%$.). Moreover, individual fibres presented a smooth surface and a cylindrical structure over the entire length (Figure 2). Oppositely, the use of additives produced thinner fibres of HA/PEO (16). These additives were capable to decrease the viscosity of the spinning solution. In this work, PEO, a FDA-approved polymer, was chosen as additive to enable HA electrospinning. It was found out that, the copolymer $\mathrm{P}(3 \mathrm{HB})-g-\mathrm{HA}_{78} / \mathrm{PEO}(\mathrm{DG}=12.8 \%$ ) exhibited the smallest diameter of all the tested compositions. Interestingly, fibre sizes around $100 \mathrm{~nm}$ were found to be particularly suitable for cell development (24).

Electrospinning method in the basic configuration produces nanofibres with random orientation (see Table S1). In addition, the electrospinning parameters could be modified to produced aligned nanofibres by using a cylindrical rotating collector $(12,13)$. To achieve the aligned structure of nanofibres in the layer, the surface speed of the collector must be set to the supercritical level. Statistical analysis of the measurement of the angle of rotation of the individual fibres in the samples showed that more than $70 \%$ of all fibres aligned. That means they are angled at $90 \pm 30^{\circ}$

From the application perspective, it is important to know whether the nanofibres fulfil the mechanical requirements of the in vivo conditions for which they will be used. For that reason, the nanomechanics of individual fibres was determined by atomic force microscope (AFM), depicted in Figure 3. This technique offered an efficient and non-destructive quantitative estimation of the topography, elasticity, viscoelasticity, and stiffness from the upper part of the individual fibre (25). The comparison of the mechanical behaviour was based on the determination of the 
linear part of the retractive force of the tip during indentation of the material proportional to the nanoindentation stiffness/hardness $(18,26)$. Thin fibres (below $100 \mathrm{~nm}$ ) could be stiffer as the measurement is influenced by the substrate during indentation or swelling by the air humidity. However, the population of fibres with sizes lower than $100 \mathrm{~nm}$ in the samples is not significant (See Table 1). On the other hand, the stiffness of the fibres with diameter above $100 \mathrm{~nm}$ is independent of the diameter, which indicates the homogeneous composition of the fibres studied. According to our results, the presence of the hydrophobic modification had a dominant role in polymer nanofibre reinforcement in $\mathrm{P}(3 \mathrm{HB})-\mathrm{g}$-HA based materials. The nanofibrous mats were soft, and are potential candidates for wound or skin applications with reinforced mechanical properties ideal for such applications (18). Furthermore, tensile properties confirmed the reinforcement observed by AFM (Figure 4).

Since the conjugate $\mathrm{P}(3 \mathrm{HB})-\mathrm{g}$-HA is water soluble, even a drop of water damages the nanofibrous structure. Therefore, to improve its stability, HA-FU was included (19). HA-FU was cross-linked in solid state by UV irradiation at $320 \mathrm{~nm}$ (Figure S6). After 10 minutes of irradiation time, the scaffold kept the original structure (Figure 5A). The formation of an interconnected structure was revealed in contact with water (Figure 5B and C). Extending UV irradiation time to $40 \mathrm{~min}$ resulted in the degradation of the nanofibrous mat (Fig. 5D). The presence of the polymer did not affect the homogeneity or size of the nanofibres (Table 1, entry 3).

Finally, cell viability was tested following ISO 10993-5. As reported in the norm, the cell viability of a sample must be above $80 \%$ to consider a material as non-cytotoxic. Figure S7 demonstrated that the material was not cytotoxic neither before nor after cross-linking.

\section{Conclusions}

In this study, $\mathrm{P}(3 \mathrm{HB})-\mathrm{g}$-HA was synthesised by combining low molecular weight $\mathrm{P}(3 \mathrm{HB})$ and hyaluronan with grafting degree up to $15 \%$. Thus, chemical modification of HA can be effectively tailored to obtain a bioconjugate, which is water soluble. The optimal conditions for electrospinning of poly(3-hydroxybutyrate) grafted to HA were found. For the first time, $\mathrm{P}(3 \mathrm{HB})$ has been incorporated in a gel-like material based on hyaluronan. Also, for the first time nanofibres containing $\mathrm{P}(3 \mathrm{HB})$ were obtained from water solutions by electrospinning. The fibre diameter was effectively modulated in the range of 100 to $400 \mathrm{~nm}$. Moreover, molecular weight was found to be a critical parameter governing the formation of uniform, smooth nanofibres. Hence, the presence of the hydrophobic modification had a 
dominant role in the nanofibre reinforcement. Overall, the formation of cross-linked structure was prepared via short photopolymerization time and showed great promise for the construction of scaffolds. The high reproducibly of the process, and non-cytotoxicity of the materials are promising in new applications i.e. in wound healing.

\section{References}

1. Li Z, Yang J, Loh XJ. Polyhydroxyalkanoates: opening doors for a sustainable future. NPG Asia Materials. 2016;8(4):e265.

2. Ali I, Jamil N. Polyhydroxyalkanoates: Current applications in the medical field. Frontiers in Biology. 2016;11(1):19-27.

3. Shishatskaya EI, Nikolaeva ED, Vinogradova ON, Volova TG. Experimental wound dressings of degradable PHA for skin defect repair. Journal of Materials Science: Materials in Medicine. 2016 ;27(11):165.

4. Ke Y, Zhang XY, Ramakrishna S, He LM, Wu G. Reactive blends based on polyhydroxyalkanoates: Preparation and biomedical application. Materials science \& engineering C, Materials for biological applications. 2017;70(2):1107-1119.

5. Iqbal HMN, Kyazze G, Tron T, Keshavarz T. Laccase from Aspergillus niger: A novel tool to graft multifunctional materials of interests and their characterization. Saudi Journal of Biological Sciences. 2016 (in press). 6. Wang Y-W, Wu Q, Chen G-Q. Reduced mouse fibroblast cell growth by increased hydrophilicity of microbial polyhydroxyalkanoates via hyaluronan coating. Biomaterials. 2003 ;24(25):4621-9.

7. Khoshakhlagh P, Moore MJ. Photoreactive interpenetrating network of hyaluronic acid and Puramatrix as a selectively tunable scaffold for neurite growth. Acta Biomater. 2015 ;16:23-34.

8. Huerta-Angeles G, Brandejsová M, Nigmatullin R, Kopecká K, Vágnerová H, Šmejkalová D, et al. Synthesis of graft copolymers based on hyaluronan and poly(3-hydroxyalkanoates). Carbohydrate Polymers. 2017 ;171:220-8.

9. Wu J, Hong Y. Enhancing cell infiltration of electrospun fibrous scaffolds in tissue regeneration. Bioactive Materials. 2016 ;1(1):56-64.

10. Dutta RC, Dey M, Dutta AK, Basu B. Competent processing techniques for scaffolds in tissue engineering. Biotechnology Advances. 2017.

11. Persano L, Camposeo A, Tekmen C, Pisignano D. Industrial Upscaling of Electrospinning and Applications of Polymer Nanofibres: A Review. Macromolecular Materials and Engineering. 2013;298(5):504-20. 
12. Pokorny M, Rebicek J, Novak J, Kotzianova A, Klemes J, Ruzickova J, Velebny V. Produced nanofibers and technological possibilities of laboratory apparatus 4SPIN. ACC journal. 2015;21:77-80.

13. Pokorny M, Novak J, Rebicek J, Klemes J, Velebný V. An Electrostatic Spinning Technology with Improved Functionality for the Manufacture of Nanomaterials from Solutions. Nanomaterials and Nanotechnology. $2015 ; 5: 17$. 14. Benešová K, Pekař M, Lapčík L, Kučerík J. Stability evaluation of n-alkyl hyaluronic acid derivates by DSC and TG measurement. Journal of Thermal Analysis and Calorimetry. 2006 ;83(2):341-8.

15. Vulpe R, Popa M, Picton L, Balan V, Dulong V, Butnaru M, et al. Crosslinked hydrogels based on biological macromolecules with potential use in skin tissue engineering. Int J Biol Macromol. 20163 ;84:174-81.

16. Ahire JJ, Robertson DD, van Reenen AJ, Dicks LMT. Polyethylene oxide (PEO)-hyaluronic acid (HA) nanofibres with kanamycin inhibits the growth of Listeria monocytogenes. Biomed Pharmacother. 2017 ;86:143-8.

17. Acevedo F, Villegas P, Urtuvia V, Hermosilla J, Navia R, Seeger M. Bacterial polyhydroxybutyrate for electrospun fibre production. Int J Biol Macromol. 2018, 106: 692-697.

18. Janković B, Pelipenko J, Škarabot M, Muševič I, Kristl J. The design trend in tissue-engineering scaffolds based on nanomechanical properties of individual electrospun nanofibres. Int J Pharm. 2013 ;455(1):338-47.

19. Huerta-Angeles G, Brandejsová M, Knotková K, Hermannová M, Moravcová M, Šmejkalová D, et al. Synthesis of photo-crosslinkable hyaluronan with tailored degree of substitution suitable for production of water resistant nanofibres. Carbohydrate Polymers. 2016; 137: 255-63.

20. Volova T, Goncharov D, Sukovatyi A, Shabanov A, Nikolaeva E, Shishatskaya E. Electrospinning of polyhydroxyalkanoate fibrous scaffolds: effects on electrospinning parameters on structure and properties. J Biomater Sci Polym Ed. 2014;25(4):370-93.

21. Andrade AP, Witholt B, Chang D, Li Z. Synthesis and Characterization of Novel Thermoplastic Polyester Containing Blocks of Poly[(R)-3-hydroxyoctanoate] and Poly[(R)-3-hydroxybutyrate]. Macromolecules. 2003 ;36(26):9830-5.

22. Peschel G, Dahse HM, Konrad A, Wieland GD, Mueller PJ, Martin DP, et al. Growth of keratinocytes on porous films of poly(3-hydroxybutyrate) and poly(4-hydroxybutyrate) blended with hyaluronic acid and chitosan. J Biomed Mater Res A. 2008 ;85(4):1072-81.

23. Arrieta MP, Samper MD, Aldas M, López J. On the Use of PLA-PHB Blends for Sustainable Food Packaging Applications. Materials. 2017;10(9):1008. 
24. Loh QL, Choong C. Three-Dimensional Scaffolds for Tissue Engineering Applications: Role of Porosity and Pore Size. Tissue Engineering Part B, Reviews. 2013 ;19(6):485-502.

25. Marrese M, Guarino V, Ambrosio L. Atomic Force Microscopy: A Powerful Tool to Address Scaffold Design in Tissue Engineering. Journal of Functional Biomaterials. 2017;8(1).

26. Knotek P, Chanova E, Rypacek F. AFM imaging and analysis of local mechanical properties for detection of surface pattern of functional groups. Materials science \& engineering C, Materials for biological applications. 2013;33(4):1963-1968. 